\title{
BOX-COUNTING DIMENSION OF OSCILLATORY SOLUTIONS TO THE EMDEN-FOWLER EQUATION
}

\author{
TAKANAO KANEMITSU AND SATOSHI TANAKA
}

Abstract. The box-counting dimension of graphs of oscillatory solutions to the Emden-Fowler equation is studied. The half-linear equation is also considered.

Mathematics subject classification (2010): 34C10, 28A80.

Keywords and phrases: Oscillatory solution, box-counting dimension, Minkowski-Bouligand dimension, Minkowski content, Emden-Fowler equation, half-linear equation.

\section{REFERENCES}

[1] F. V. AtKinson, On second-order non-linear oscillations, Pacific J. Math. 5 (1955), 643-647.

[2] S. BELOHOREC, Oscillatory solutions of certain nonlinear differential equations of second order, Mat. Fyz. Cas. Slovensk. Akad. Vied. 11 (1961), 250-255.

[3] O. DošLÝ AND P. ŘEHÁK, Half-linear differential equations, North-Holland Mathematics Studies 202, Elsevier Science B. V., Amsterdam, 2005.

[4] P. DRÁBEK AND R. MANÁSEVICH, On the closed solution to some nonhomogeneous eigenvalue problems with p-Laplacian, Differential Integral Equations 12 (1999), 773-788.

[5] K. Falconer, Fractal Geometry. Mathematical Fondations and Applications, John Willey-Sons, 1999.

[6] I. T. KIgURADZE, On the oscillatory and monotone solutions of ordinary differential equations, Arch. Math. (Brno) 14 (1978), 21-44.

[7] I. T. Kiguradze AND T. A. Chanturia, Asymptotic properties of solutions of nonautonomous ordinary differential equations, Translated from the 1985 Russian original, Mathematics and its Applications (Soviet Series) 89, Kluwer Academic Publishers Group, Dordrecht, 1993.

[8] T. KusANO AND M. NAITO, Unbounded nonoscillatory solutions of nonlinear ordinary differential equations of arbitrary order, Hiroshima Math. J. 18 (1988), 361-372.

[9] M. K. KWONG, M. PašIĆ AND J. S. W. Wong, Rectifiable oscillations in second-order linear differential equations, J. Differential Equations 245 (2008), 2333-2351.

[10] M. NAITO, A remark on the existence of slowly growing positive solutions to second order superlinear ordinary differential equations, No. DEA Nonlinear Differential Equations Appl. 20 (2013), 1759-1769.

[11] M. PAšIć, Fractal oscillations for a class of second order linear differential equations of Euler type, J. Math. Anal. Appl. 341 (2008), 211-223.

[12] M. PašIĆ AND S. TANAKA, Fractal oscillations of self-adjoint and damped linear differential equations of second-order, Appl. Math. Comput. 218 (2011), 2281-2293.

[13] M. PAŠIĆ AND S. TANAKA, Fractal oscillations of chirp functions and applications to second-order linear differential equations, Int. J. Differ. Equ. 2013, Art. ID 857410, 11 pp.

[14] M. PAŠIĆ AND J. S. W. WONG, Rectifiable oscillations in second-order half-linear differential equations, Ann. Mat. Pura Appl. (4) 188 (2009), 517-541.

[15] S. TAKEUCHI, Multiple-angle formulas of generalized trigonometric functions with two parameters, J. Math. Anal. Appl. 444 (2016), 1000-1014.

[16] C. Tricot, Curves and Fractal Dimension, Springer-Verlag, New York, 1995.

[17] J. S. W. Wong, On the generalized Emden-Fowler equation, SIAM Rev. 17 (1975), 339-360. 
[18] J. S. W. Wong, On rectifiable oscillation of Emden-Fowler equations, Mem. Differential Equations Math. Phys. 42 (2007), 127-144. 